\title{
sciendo
}

\author{
Current Issues in Pharmacy and Medical Sciences \\ Former ly ANNALES UNIVERSITATIS MARIAE CURIE-SKLODOWSKA, SECTIO DDD, PHARMACIA \\ journal homepage: http://www.curipms.umlub.pl/
}

\section{Origins, pathophysiology, diagnosis, vaccination and prevention of Chikungunya virus}

\author{
Md. Rajdoula Rafe ${ }^{1 *}{ }^{\circledR}$, Syeda Naureen Ahmed ${ }^{2}, Z_{\text {ebunnesa Ahmed }}^{2}$
}

${ }^{1}$ Department of Pharmacy, Jagannath University, Dhaka, Bangladesh

${ }^{2}$ Department of Pharmacy, Southeast University, Dhaka, Bangladesh

\begin{tabular}{ll}
\hline ARTICLE INFO & ABSTRACT \\
\cline { 1 - 2 } $\begin{array}{l}\text { Received } 30 \text { May 2018 } \\
\text { Accepted 20 July 2018 }\end{array}$ & $\begin{array}{l}\text { Chikungunya virus is an Alphavirus that possesses characteristics similar to that of an } \\
\text { arthropod-borne virus. Chikungunya virus has been one of the major concerns for the } \\
\text { Chikungunya, } \\
\begin{array}{l}\text { arthralgia, } \\
\text { pathogenesis, } \\
\text { diagnosis, } \\
\text { prevention. }\end{array}\end{array} \begin{array}{l}\text { last few decades due to its nature of explosive spreading throughout the world. This } \\
\text { article is intended to give detailed information about Chikungunya virus, and includes its } \\
\text { pathogenesis, origins, diagnosis, treatment and prevention. Although, recent researches } \\
\text { suggests various approaches to treating Chikungunya virus, extensive literature search on } \\
\text { Chikungunya virus has revealed that, currently, there is no effective treatment available } \\
\text { and the virus is greatly dependent on its vectors. Patients affected by Chikungunya virus } \\
\text { mainly show symptoms of fever, arthralgia, joint pain and skin rash. Since there is no } \\
\text { effective treatment available, public awareness is the most significant factor for potential } \\
\text { prevention against Chikungunya virus. }\end{array}$ \\
\hline
\end{tabular}

\section{INTRODUCTION}

Chikungunya virus (CHIKV) is a mosquito-transmitted Alphavirus belonging to the family Togaviridae that formed the 2006 Asian outbreak [1]. The clinical manifestation of patients affected by the virus includes febrile fever and mild to severe arthralgia with or without rash in the skin [2-5]. Although the Indian Ocean outbreak was transmitted through Aedes mosquitoes, a report suggested that Chikungunya virus could also be transmitted through the Anopheles stephensi mosquito [1,6]. In addition, other vertebrates like monkeys act as reservoirs for Chikungunya virus. Chikungunya virus was first identified in mid-1950 in Tanzania. Here, it occurred during a sylvatic cycle in the sub-Saharan Africa. Later, it became endemic within an urban cycle in Asia [7]. The African sylvatic cycle was maintained in non-human animals, small mammals like bats and monkeys and in mosquitoes [8]. Even though serological tests show non-human primates are the main host for CHIKV, isolation studies confirm that Aedes mosquitoes are the main vectors for CHIKV transmission [9]. Three types of CHIKV genotype have been recognized namely Asian, western African and east-central-south African [7,10].

Most of the symptoms caused by CHIKV resolve over time but in some cases, severe joint pain may persist

\footnotetext{
* Corresponding author

e-mail: rafi.soyeb@gmail.com
}

for years. This can lead to bending or stooping posture [11]. In neonates, CHIKV has been shown to cause meningoencephalitis, in addition to high morbidity rate. The first case of neonatal encephalitis induced by CHIKV was reported in Brazil [12].

\section{Methodology}

To complete this literature review, information was collected from several websites and journals published by reputed publishers, for example, PubMed, PubMed Central, Springer, Elsevier, Google Scholar and other journals that contained articles about Chikungunya virus. Keywords used for extensive searching include Chikungunya virus, Chikungunya in Asia, Chikungunya in Bangladesh, Chikungunya virus and recent outbreaks of Chikungunya in Bangladesh etc. Appropriate referencing and citations were used during writing this review.

\section{Origins of Chikungunya virus}

The Chikungunya virus (CHIKV) is an RNA virus belonging to the genus Alphavirus and family Togaviridae. CHIKV contains a capsid of 60-70 nm diameter and a phospholipid envelope. This indicates temperature sensitivity above $58^{\circ} \mathrm{C}[13,14]$. Six of the viruses amongst 28 other Alphavirus genuses can cause joint pain or other joint disorders in humans. These six viruses are Chikungunya 
virus, Mayaro virus, O'nyong-nyong virus, Ross River virus, Sindbis virus and Barmah Forest virus [13]. Viruses of the Alphavirus genus have common antigenic determinants $[14,15]$.

Although CHIKV was first identified in 1950 in Tanzania, the exact time of the virus's origination is still unknown. O'nyong-nyong virus (ONNV) resembles CHIKV closely and it caused an outbreak in Africa through Anopheles mosquitoes almost 100 years before CHIKV was identified [16]. According to the phylogenic data analysis and other relationships between CHIKV and ONNV, it is believed that these viruses have evolved in the region of sub-Saharan Africa; however, the exact region of origination is yet to be found. In Africa, CHIKV mostly infects humans in the rural area by a sylvatic transmission cycle. Infections in the urban area are thought to be caused due to human migration and traveling. In epidemic periods, humans act as main reservoirs. Aedes aegypti and Aedes albopictus are the two principal vectors that are responsible for the transmission of CHIKV $[17,18]$. Monkeys, rodents, birds, and buffalos are also involved in the transmission cycle during the inter-epidemic periods, acting as reservoirs [19].

\section{Clinical Pathophysiology}

Infection caused by CHIKV is highly similar to infection caused by dengue virus, thereby making it difficult to differentiate. A CHIKV incubation period usually occurs in the range of 1-12 days and the average range of incubation is 2-4 days [20-24]. The later period of incubation is symptomatic with the onset of fever, arthralgia, myalgia, headache and skin rash [20-24]. Although, most of the patients recover from arthralgia within 1-2 weeks after the onset of disorders, in some cases, the arthralgia may persist for several months to years [25-29]. Numerous studies have found long-lasting arthralgia in CHIKV affected patients [25-29].

Recently, a study on the outbreak of CHIKV in Reunion Island reported that symptoms in affected people might take up to 14 days to appear after the onset of CHIKV. During these 14 days, two stages were recognized, namely the 'viral stage' from 1 to 4 days with decreasing viremia, and the 'convalescent stages' from day 5 to 14 without any detectable viremia. Between these two stages, the second stage showed slower clinical improvement than the first stage [30].

\section{Diagnosis}

There are limited diagnostic measures and opportunities to identify CHIKV due to the lack of research and knowledge on this virus. Furthermore, a successful control method is yet to be identified to manage CHIKV outbreaks. As of fall 2013, there are an estimated 1.2 million suspected CHIKV patients, but among them, only $2 \%$ have been confirmed by laboratory diagnostics. The majority of the infections in humans were identified with the combination of RT-PCR and IgM ELISA techniques. However, due to high cost and limited availability, in the local areas where CHIKV infections were severe, the use of diagnostic tests turned out to be insufficient. Sissoko et al. employed a retrospective serological test after the outbreak in 2006, in Mayotte Island, and reported that fever in combination with polyarthralgia had $84 \%$ sensitivity, $74 \%$ positive predictive value and $84 \%$ negative predictive value [31]. In comparison with the dengue virus, CHIKV is mostly presented with arthralgia and rash, whereas dengue is presented with myalgia and leucopoenia [32]. Other reported symptoms more related to CHIKV are lymphopenia, increased liver enzymes, and increased creatinine levels [33,34].

A study suggested that the enzyme-linked immunosorbent assay ((HCAb IgG2 and IgG3) based on the camel antibody is a reliable and accurate technique for identifying Chikungunya virus infections [35]. The assay result showed high precision and coefficient of variation for intra-plate and inter-plate (5\% and $8 \%$, respectively) in both types of assays (HCAb IgG2 and IgG3).

The National Virology Laboratory of Nicaragua developed two IgM ELISA capture systems (MAC-ELISA) and two inhibitions ELISA methods (IEM) in 2014-2015 for the diagnosis of acute CHIKV infections and measurement of total antibodies that worked against CHIKV. Monoclonal antibodies and hyper-immune serum were used to develop the assay techniques. Herein, sensitivity of $95.7 \%$ and specificity of $88.95 .9 \%$ were observed during clinical evaluation of the four assays, in comparison with the real-time RT-PCR (Reverse Transcription-Polymerase Chain Reaction) assay recommended by Centers for Disease Control (CDC) [36].

A recent quantitative RT-PCR study based on a SYBR Green I showed a 10-fold increase in sensitivity than conventional RT-PCR [37]. In another report, to amplify the nsP2 region of the CHIKV genome, researchers used derivatives of DANP (2, 7-diamino-1, 8-naphthyridine)-labeled cytosine bulge hairpin primers, then measured the fluorescence emitted from DANP and primer complexes after PCRs [38].

In a different study, IgM and IgG antibodies working against CHIKV were evaluated by using a specific ELISA technique in 604 patients. After comparing patients with CHIKV and without CHIKV, a statistical significance was observed for IgG and $\operatorname{IgM}(\mathrm{p}<0.0001)$ [39].

\section{Treatment}

Chikungunya usually resolves with time without any treatment because there is no approved antiviral treatment yet discovered. Symptoms like fever and pain can be treated with anti-pyretic and analgesic, for example, paracetamol. CHIKV induced arthralgia can also be treated with NSAIDs (Nonsteroidal anti-inflammatory drugs). Ribavirin is an antiviral drug that can act against various RNA viruses, but its activity against Alphaviruses is not well studied [40]. Recently, however, some classes of compounds have been found to be effective in inhibiting CHIKV replication by either targeting the virus or the host [41].

Ravichandran and Manian report that ribavirin had moderate effects against the arthralgia caused by CHIKV. However, this report was based on a limited number of patients. To establish the effects of ribavirin against CHIKV associated diseases, an extensive study of this drug on a broad-spectrum analysis of CHIKV affected patients is required [42]. The availability of limited antiviral drugs and the destructive nature of the CHIKV suggest that vaccination will be the most effective way of treating CHIKV both in terms of cost and efficacy [43]. 


\section{Prevention \& Control}

The vector is the most important factor to control in CHIKV epidemics, due to the lack of effective treatment options. Transmission control of CHIKV through managing the growth of the vector could be an effective approach against CHIKV. Hence, breeding sites of vectors should be controlled to eradicate the vector as routine larviciding in public catch basins can inhibit the transmission and potential epidemics of CHIKV. Public awareness is also necessary to eliminate vectors of CHIKV. Personal awareness like sleeve clothing, covering bed sites and windows with net and using repellents spray can also be applied for vector control.

Parricidal activities can be promoted by involving private citizens to reduce transmission of CHIKV [44].

Vaccination: Usually, vaccines are highly effective for treating vector-borne diseases. As CHIKV spreads rapidly with high attacking rate, novel therapeutic agent will also be valuable [45]. A monoclonal antibody (dMAb) containing anti-Chikungunya virus encoding DNA plasmids was designed to use as a prophylaxis therapy. The monoclonal antibody was delivered through an electroporation-mediated delivery system and its efficacy and limitations against virus was compared against conventional vaccine and immunotherapy. After treating mice models, the dMAb neutralized CHIKV isolates rapidly and protected recipients from the virus. However, the combination of dMAb and CHIKV DNA vaccine gave a more rapid and longer lasting protection against CHIKV [46].

Modification of specific viral sequences is another approach to attenuate CHIKV and it might act as a vaccination, for example, nucleolar localization sequence (NoLS) in capsid protein can be modified to attenuate CHIKV [47]. Herein, modification of CHIKV-NoLS demonstrated less replication in mice and mosquito. In addition, mice treated with modified CHIKV-NoLS showed no disease progression compared to the mice with normal virus. Immunized mice also showed protection against other viruses like CHIKV [48].

Roques et al. developed three types of vaccines and evaluated these againsta non-human primate model. An attenuated sequence of CHIKV $(\Delta 5 \mathrm{nsP} 3)$, a DNA-launched RNA replicon with encoding of CHIKV envelope proteins (DREP-E) and a DREP-E prime with modified Ankara encoding CHIKV capsid showed protection against a wild type Chikungunya virus. These vaccinations developed both humoral and cellular immunity and proved to be safe without showing any clinical signs [49]. Virus-like particles (VLP) containing the CHIKV envelope and capsid in their surface, as well as recombinant Measles virus with CHIKV polypeptides were able to replicate inside the host cells. This approach can be used to produce vaccine for the prevention of Chikungunya virus infection. [50].

Application of insect repellants: Insect repellants such as the CDC-approved N,N-diethly-3-methylbenzamide (DEET), picaridin, oil of lemon eucalyptus or para-menthane-3,8-diol, and IR3535 (ethyl butylacetylaminopropionate) can be used to prevent CHIKV transmission. If there is a risk of mosquito transmitted diseases, repellants should be used on exposed skin during the day and also at night. Application frequency of repellants depend on the concentration of the repellants; lower concentration of repellants need to be applied more frequently than higher concentration [51]. DEET is the most preferred insect repellants due to its effectiveness against aggressive biting mosquitoes compared to other non-CDC recommended repellants [52].

Use of mosquito nets over beds: Vector mosquitoes usually bite during the day and which is why bed nets are necessary while sleeping in the day, especially in CHIKV affected areas [53]. An insecticide impregnated mosquito net is an effective approach against vector mosquitoes [54].

Protective clothing: Travelers and people in CHIKV affected areas should use appropriate clothing to minimize skin exposure to mosquitoes. Usually, mosquitoes are less attracted towards light color clothing. Loose fitting but tightly woven fabrics are also preferable. Furthermore, insect repellants applied to clothes are longer lasting than when applied to the skin.

Removal of standing water: The mosquitoes transmitting CHIKV usually inhabit stagnant water. Therefore, eliminating stagnant water systems by using sealed containers or covers could prevent the growth of mosquito vectors. People should eliminate standing water around their living quarters and houses to prevent mosquitoes breeding environment. Standing water should be removed at least once a week as mosquitoes need 8-10 days to develop from egg to adult. Even a small amount of stagnant water should be eliminated.

\section{CONCLUSION}

In Bangladesh, most of the patients with Chikungunya virus remain undiagnosed or misdiagnosed with dengue virus. This is due to the lack of diagnostic facilities and people presenting similar symptoms caused by the dengue virus. A successful vaccine against Chikungunya virus can be produced in the future, but caution should be taken during its design and development. Since vectors are the most important determinants for spreading Chikungunya virus in the epidemic form, house-to-house measures need to be taken to eliminate vector breeding places by encouraging public awareness [55].

\section{CONFLICT OF INTERESTS}

Authors declare that they have no conflict of interests.

\section{ACKNOWLEDGEMENT}

The authors acknowledge to the Department of Pharmacy, Jagannath University, Dhaka, Bangladesh for providing technical support.

\section{ORCID iDs}

Md. Rajdoula Rafe (Dhttps://orcid.org/0000-0003-4200-861X

\section{REFERENCES}

1. Schuffenecker I, Iteman I, Michault A, Murri S, Frangeul L, Vaney MC, et al. Genome microevolution of chikungunya viruses causing the Indian Ocean outbreak. PLoS Med. 2006;3(7):263.

2. Deller JJ, Russell PK. An analysis of fevers of unknown origin in American soldiers in Vietnam. Ann Inter Med. 1967;66(6):1129-43. 
3. McGill PE. Viral infections: $\alpha$-viral arthropathy. Best Prac \& Res Clin Rheumat. 1995;9(1):145-50.

4. Adebajo AO. Rheumatic manifestations of tropical diseases. Curr Opin Rheumatol. 1996;8(1):85-9.

5. Ligon BL. Reemergence of an unusual disease: the chikungunya epidemic. In Seminars in pediatric infectious diseases. WB Saunders. 2006:17(2):99-104.

6. Yadav P, Gokhale MD, Barde PV, Singh DK, Mishra AC, Mourya DT. Experimental transmission of Chikungunya virus by Anopheles stephensi mosquitoes. Act Virol. 2003;47(1):45-7.

7. Pialoux G, Gaüzère BA, Jauréguiberry S, Strobel M. Chikungunya, an epidemic arbovirosis. Lan Infect Dis. 2007;7(5):319-27.

8. Diallo M, Thonnon J, Traore-Lamizana M, Fontenille D. Vectors of Chikungunya virus in Senegal: current data and transmission cycles. Am J Trop Med and Hyg. 1999;60(2):281-6.

9. Jupp PG. Chikungunya virus disease. Arbovirus: epidemiology and ecology. 1988:137.

10. Ng LC, Hapuarachchi HC. Tracing the path of Chikungunya virus evolution and adaptation. Infect Gen Evol. 2010;10(7):876-85.

11. Robinson MC. An epidemic of virus disease in Southern Province, Tanganyika Territory, in 1952-53. I. Clinical features. Trans $R$ Soc Trop Med Hyg. 1955;49(1):28-32.

12. Bandeira AC, Campos GS, Sardi SI, Rocha VF, Rocha GC. Neonatal encephalitis due to Chikungunya vertical transmission: first report in Brazil. ID Cases. 2016;5:57-9.

13. Khan AH, Morita K, del Carmen Parquet M, Hasebe F, Mathenge EG, Igarashi A. Complete nucleotide sequence of chikungunya virus and evidence for an internal polyadenylation site. J Gen Virol. 2002;83(12):3075-84.

14. Strauss JH, Strauss EG. The alphaviruses: gene expression, replication, and evolution. Microbiol reviews. 1994;58(3):491-562.

15. Yadav P, Shouche YS, Munot HP, Mishra AC, Mourya DT. Genotyping of Chikungunya virus isolates from India during 19632000 by reverse transcription-polymerase chain reaction. Act Virol. 2003;47(2):125.

16. Vanlandingham DL, Hong C, Klingler K, Tsetsarkin K, McElroy KL, Powers AM, et al. Differential infectivities of o'nyong-nyong and chikungunya virus isolates in Anopheles gambiae and Aedes aegypti mosquitoes. Am J Trop Med Hyg. 2005;72(5):616-21.

17. Jupp PG, McIntosh BM, Dos Santos I, De Moor P. Laboratory vector studies on six mosquito and one tick species with chikungunya virus. Trans R Soc Trop Med Hyg. 1981;75(1):15-9.

18. Rao TR. Vectors of dengue and chikungunya viruses: a brief review. Ind J Med Res. 1964;52:719-26.

19. R. C. Kading, E. M. Borland, M. Cranfield, A. M. Powers. Prevalence of antibod-ies to alphaviruses and flaviviruses in free-ranging game animals and nonhuman primates in the greater congo basin. J Wildl Dis. 2013;49:587-599.

20. Lam SK, Chua KB, Hooi PS, Rahimah MA, Kumari S, Tharmaratnam $\mathrm{M}$, et al. Chikungunya infection-an emerging disease in Malaysia. Southeast A J Trop Med Pub Health. 2001 Sep;32(3):447-51.

21. Van den Bosch C. A role for RNA viruses in the pathogenesis of Burkitt's lymphoma: the need for reappraisal. Adv Hematol. 2012; 2012.

22. Borgherini G, Poubeau P, Staikowsky F, Lory M, Moullec NL, Becquart JP, et al. Outbreak of chikungunya on Reunion Island: early clinical and laboratory features in 157 adult patients. Clin Infect Dis. 2007 Jun 1;44(11): 1401-7.

23. Queyriaux B, Simon F, Grandadam M, Michel R, Tolou H, Boutin JP. Clinical burden of chikungunya virus infection. Lan Infect Dis. 2008;8(1):2-3.

24. Lemant J, Boisson V, Winer A, Thibault L, André H, Tixier F, et al. Serious acute chikungunya virus infection requiring intensive care during the Reunion Island outbreak in 2005-2006. Crit care Med. 2008;36(9):2536-41.

25. Simon F, Parola P, Grandadam M, Fourcade S, Oliver M, Brouqui P, et al. Chikungunya infection: an emerging rheumatism among travelers returned from Indian Ocean islands. Report of 47 cases. Med. 2007;86(3):123-37.
26. Sissoko D, Malvy D, Ezzedine K, Renault P, Moscetti F, Ledrans M, et al. Post-epidemic Chikungunya disease on Reunion Island: course of rheumatic manifestations and associated factors over a 15-month period. PLoS Negl Trop Dis. 2009;3(3):e389.

27. Manimunda SP, Vijayachari P, Uppoor R, Sugunan AP, Singh SS, Rai SK, et al. Clinical progression of chikungunya fever during acute and chronic arthritic stages and the changes in joint morphology as revealed by imaging. Trans R Soc Trop Med Hyg. 2010;104(6):392-9.

28. Brighton SW, Prozesky OW, De La Harpe AL. Chikungunya virus infection-A retrospective study of 107 cases. South Afr Med J. 1983;68(9):313-5.

29. Borgherini G, Poubeau P, Jossaume A, Gouix A, Cotte L, Michault A, et al. Persistent arthralgia associated with chikungunya virus: a study of 88 adult patients on reunion island. Clin Infect Dis. 2008; 47(4):469-75.

30. Thiberville SD, Boisson V, Gaudart J, Simon F, Flahault A, De Lamballerie X. Chikungunya fever: a clinical and virological investigation of outpatients on Reunion Island, South-West Indian Ocean. PLoS Negl Trop Dis. 2013;7(1):e2004.

31. Sissoko D, Ezzedine K, Moendandzé A, Giry C, Renault P, Malvy D. Field evaluation of clinical features during chikungunya outbreak in Mayotte, 2005-2006. Trop Med \& Int Health. 2010;15(5):600-7.

32. Zim MM, Sam IC, Omar SS, Chan YF, AbuBakar S, Kamarulzaman A. Chikungunya infection in Malaysia: comparison with dengue infection in adults and predictors of persistent arthralgia. J Clin Virol. 2013;56(2):141-5.

33. Staikowsky F, Talarmin F, Grivard P, Souab A, Schuffenecker I, Le Roux K, et al. Prospective study of Chikungunya virus acute infection in the Island of La Reunion during the 2005-2006 outbreak. PloS one. 2009;4(10):e7603.

34. Nkoghe D, Kassa RF, Caron M, Grard G, Mombo I, Bikié B, et al. Clinical forms of chikungunya in Gabon, 2010. PLoS Negl Trop Dis. 2012;6(2):e1517.

35. Kimani J, Osanjo GO, Sang R, Ochieng J, Mulaa F. Development of Dromedary Antibody-based Enzyme Linked Immunosorbent Assay for Detecting Chikungunya virus Infections. Afr J Pharm Therap. 2017;6(2);109-16.

36. Galo SS, González K, Téllez Y, García N, Pérez L, Gresh L, et al. Development of in-house serological methods for diagnosis and surveillance of chikungunya. Rev Panam de Sal Públ. 2017;41:e56.

37. Agarwal A, Singh AK, Sharma S, Soni M, Thakur AK, Gopalan N, et al. Application of Real-time RT-PCR in vector surveillance and assessment of replication kinetics of an emerging novel ECSA genotype of Chikungunya virus in Aedes aegypti. J Virol Meth. 2013;193(2):419-25.

38. Chen H, Takei F, Koay ES, Nakatani K, Chu JJ. A novel DANPcoupled hairpin RT-PCR for rapid detection of Chikungunya virus. J Mol Diagn. 2013;15(2):227-33.

39. Rueda JC, Angarita JI, Santos AM, Saldarriaga EL, Pelaez-Ballestas I, López-Morales P, et al. SAT0574 Performance of immunoglobulin $M$ and $G$ (IGM and IGG) antibodies against chikungunya virus (CHIKV) by enzyme-linked immunosorbent (ELISA) technique. Ann Rheum Dis. 2017;76:993.

40. Smee DF, Alaghamandan HA, Kini GD, Robins RK. Antiviral activity and mode of action of ribavirin 5'-sulfamate against Semliki Forest virus. Antv Res. 1988;10(6):253-62.

41. Abdelnabi R, Neyts J, Delang L. Chikungunya virus infections: time to act, time to treat. Curr Opin Virol. 2017;24:25-30.

42. Ravichandran R, Manian M. Ribavirin therapy for Chikungunya arthritis. J Infect Developing Countries. 2008;2(02):140-2.

43. Briolant S, Garin D, Scaramozzino N, Jouan A, Crance JM. In vitro inhibition of Chikungunya and Semliki Forest viruses replication by antiviral compounds: synergistic effect of interferon- $\alpha$ and ribavirin combination. Antv Res. 2004;61(2):111-7.

44. Guzzetta G, Trentini F, Poletti P, Baldacchino FA, Montarsi F, Capelli G, et als. Effectiveness and economic assessment of routine larviciding for prevention of chikungunya and dengue in temperate urban settings in Europe. PLoS Negl Trop Dis. 2017;11(9):e0005918.

45. Powers AM. Vaccine and Therapeutic Options To Control Chikungunya Virus. Clin Mbio Reviews. 2018;31(1):e00104-16. 
46. Muthumani K, Block P, Flingai S, Muruganantham N, Chaaithanya IK, Tingey C, et al. Rapid and long-term immunity elicited by DNA-encoded antibody prophylaxis and DNA vaccination against chikungunya virus. J Infect Dis. 2016;214(3):369-78.

47. Rowland RR, Yoo D. Nucleolar-cytoplasmic shuttling of PRRSV nucleocapsid protein: a simple case of molecular mimicry or the complex regulation by nuclear import, nucleolar localization and nuclear export signal sequences. Vir Res. 2003;95(1-2):23-33.

48. Taylor A, Liu X, Zaid A, Goh LY, Hobson-Peters J, Hall RA, et al. Mutation of the n-terminal region of chikungunya virus capsid protein: Implications for vaccine design. Mbio. 2017;8(1): e01970-16.

49. Roques P, Ljungberg K, Kümmerer BM, Gosse L, DereuddreBosquet N, Tchitchek N, et al. Attenuated and vectored vaccines protect nonhuman primates against Chikungunya virus. JCI Ins. 2017;2(6);1-20

50. Tangy F, Brandler S, Despres P, Habel A, inventors; THEMIS BIOSCIENCE GMBH, Institut Pasteur, Centre National de la Recherche Scientifique CNRS, assignee. Recombinant measles virus expressing Chikungunya virus polypeptides and their applications. United States patent US 9,655,961. 2017.
51. Fradin MS, Day JF. Comparative efficacy of insect repellents against mosquito bites. N Engl J Med. 2002;347(1):13-8.

52. Mirzaian E, Durham MJ, Hess K, Goad JA. Mosquito-Borne illnesses in travelers: a review of risk and prevention. Pharmtherap: J Human Pharm Drug Therap. 2010;30(10):1031-43.

53. Nasci RS, Zielinski-Gutierrez E, Wirtz RA, Brogdon WG. Protection against mosquitoes, ticks, other insects and arthropods. 2014 (Yellow book).

54. Patterson J, Sammon M, Garg M. Dengue, Zika and Chikungunya: emerging arboviruses in the new world. Westn J Emerg Med. 2016; 17(6):671.

55. Chang LJ, Dowd KA, Mendoza FH, Saunders JG, Sitar S, Plummer SH, et al. Safety and tolerability of Chikungunya virus-like particle vaccine in healthy adults: a phase 1 dose-escalation trial. Lan. 2014; 384(9959):2046-52. 